\title{
A New Method for Measurement of the Vitrification Rate of Earthenware Texture by Scanning Electron Microscope
}

\author{
Eun Jung Moon, Su Kyeong Kim, Min Su Han, Eun Woo Lee, Jun Su Heo, \\ and Han Hyoung Lee \\ Conservation Science Division, National Research Institute of Cultural Heritage, 472 Munji-dong, \\ Yuseong-gu, Daejeon 305-380, Korea
}

\begin{abstract}
A new method for determining the vitrification rate of pottery depending on the firing temperature was devised using secondary electron images (SEI) of scanning electron microscope (SEM). Several tests were performed to establish the appropriate operating conditions of SEM and reproducibility as well as to examine the applicability of the method. The grayscale values converted from each pixel of SEI were used to determine the vitrification rate of pottery, which in our study were artificially fired specimens composed of three types of clay. A comparison between the vitrification rate value and appearance temperature of minerals shows that mullite formation starts at $1,100^{\circ} \mathrm{C}$, during which the vitrification rate rapidly increases by over $10 \%$. In consequence, the result presented here demonstrates that the new method can be applied to estimate the firing temperature of pottery.
\end{abstract}

Key words: SEM, pottery, vitrification, XRD, firing temperature, pixel, grayscale

\section{INTRODUCTION}

Potteries are among the first composite materials manufactured and utilized by human beings. From the early times, they have been fabricated in a controlled way, specific to suitable applications (Hein et al., 2008). Estimating the firing temperature for potteries used by early humans can provide clues on identifying the purposes of the potteries in their daily routines at that time (Van Olphen \& Fripat, 1979). In general, the texture of a pottery is vitrified by a firing process, and the vitrification rate is determined by the firing conditions. The vitrification rate provides useful information for characterizing the quality of a pottery, as it influences the microstructural and physical properties of the pottery, relevant to its suitability for various uses (Sandrolini et al., 1993). Microstructural analysis by scanning electron microscope (SEM) allows assessment of the textural features of the potteries caused by the firing process, which, if combined with petrographic and mineralogical data, can yield a rough estimate of the equivalent firing temperatures (Maniatis \& Tite, 1981; Kilikoglou, 1994).

Several studies have been performed on pieces of ancient potteries using SEM in the past years aiming at analyzing the development of vitrification (Maniatis \& Tite, 1975, 1978, 1981; Noll et al., 1975; Maniatis et al., 1983). Recently, studies have been carried out to estimate the firing temperature based on earlier studies on vitrification by careful observation of the size and shape variation of the pores (Andaloro et al., 2010) or by comparison of the microstructure (Moropoulou et al., 1995; Velraj et al., 2009), which is inevitably subjective to each researcher's view. The limited

() MICROSCOPY SOCIETY OF AMERICA 2013

${ }^{\star}$ Corresponding author. E-mail: lhh1025@hanmail.net number of studies to date is because of the lack of numerical data on the vitrification rate and firing temperature, which demands on the establishment of a numerical basis for SEM studies on potteries. In this study, we developed a new method to chart the rate of vitrification using SEM and secondary electron images (SEI). In addition, the applicability of the estimation of the firing temperature of pottery was evaluated by comparing the acquired value of vitrification with X-ray diffraction (XRD) analysis.

\section{Materials and Methods}

\section{Principles of Extracting the Numerical Value of the} Vitrification Rate from SEI of the Specimen Surface

Clay particles that constitute pottery become vitreous on melting at an adequate firing temperature and form compact and homogenous textures that have a regular hardness, which allows mirror/reflective finish of a specimen surface during the polishing process. However, if the firing temperature is low, the clay particles do not melt, and thus the vitrification of the texture does not occur, resulting in a rough surface after polishing because of the irregular hardness. These morphologies of flat or rough specimen surfaces can be observed using SEM, as the amount of emitted secondary electrons is heavily dependent on the surface condition of the specimen, which affects the contrast and brightness of the SEM image. In case of clay specimens composed of elements with similar atomic numbers, the brightness is mainly related to the morphological factor only, i.e., specimens having a rough surface result in an image with a clear contrast, whereas flat specimens are imaged with plain brightness. Variations in brightness determined from SEI can be converted to numerical data using the profiling function of image analysis softwares. 
Table 1. The Mineral Composition and Vitrification Rate of the Specimens with Regard to the Initial Clay Types (OH, $\mathrm{OG}$, and $\mathrm{OY})$ and Firing Temperatures $\left(600-1,200^{\circ} \mathrm{C}\right) .^{\star}$

\begin{tabular}{|c|c|c|c|c|c|c|c|c|}
\hline \multirow[b]{2}{*}{ Clay } & \multicolumn{2}{|c|}{ Composition $^{\mathrm{a}}$} & \multirow{2}{*}{$\begin{array}{c}\text { Firing } \\
\text { Temperature } \\
\left({ }^{\circ} \mathrm{C}\right)\end{array}$} & \multirow[b]{2}{*}{ Mineral $^{\mathrm{b}}$} & \multicolumn{4}{|c|}{ Vitrification Rate } \\
\hline & $\mathrm{RO}_{2} / \mathrm{R}_{2} \mathrm{O}_{3}$ & $\left(\mathrm{RO}+\mathrm{R}_{2} \mathrm{O}\right) / \mathrm{R}_{2} \mathrm{O}_{3}$ & & & Mean & $\mathrm{SD}$ & SE & RSD \\
\hline \multirow[t]{7}{*}{$\mathrm{OH}$} & 3.41 & 0.47 & 600 & $\mathrm{Q}, \mathrm{Pl}, \mathrm{O}, \mathrm{M}, \mathrm{T}$ & 0.8 & 0.7 & 0.3 & 0.8 \\
\hline & & & 700 & $\mathrm{Q}, \mathrm{Pl}, \mathrm{O}, \mathrm{M}, \mathrm{T}$ & 0.6 & 0.7 & 0.3 & 1.0 \\
\hline & & & 800 & $\mathrm{Q}, \mathrm{Pl}, \mathrm{O}, \mathrm{M}, \mathrm{T}$ & 2.8 & 2.3 & 1.0 & 0.8 \\
\hline & & & 900 & $\mathrm{Q}, \mathrm{Pl}, \mathrm{O}, \mathrm{M}, \mathrm{T}$ & 2.9 & 1.3 & 0.6 & 0.5 \\
\hline & & & 1,000 & $\mathrm{Q}, \mathrm{Pl}, \mathrm{T}$ & 2.9 & 1.5 & 0.7 & 0.5 \\
\hline & & & 1,100 & $\mathrm{Q}, \mathrm{Pl}, \mathrm{Mu}, \mathrm{H}, \mathrm{E}$ & 13.2 & 4.2 & 1.9 & 0.3 \\
\hline & & & 1,200 & $\mathrm{Q}, \mathrm{Pl}, \mathrm{Mu}, \mathrm{H}, \mathrm{E}$ & 78.6 & 8.6 & 3.8 & 0.1 \\
\hline \multirow[t]{7}{*}{ OG } & 5.85 & 0.35 & 600 & $\mathrm{Q}, \mathrm{Pl}, \mathrm{O}, \mathrm{M}$ & 0.8 & 0.3 & 0.1 & 0.3 \\
\hline & & & 700 & $\mathrm{Q}, \mathrm{Pl}, \mathrm{O}, \mathrm{M}$ & 1.4 & 0.7 & 0.3 & 0.5 \\
\hline & & & 800 & $\mathrm{Q}, \mathrm{Pl}, \mathrm{O}, \mathrm{M}$ & 0.9 & 0.7 & 0.3 & 0.9 \\
\hline & & & 900 & $\mathrm{Q}, \mathrm{Pl}, \mathrm{O}, \mathrm{M}$ & 0.6 & 0.6 & 0.3 & 0.9 \\
\hline & & & 1,000 & $\mathrm{Q}, \mathrm{Pl}, \mathrm{O}$ & 4.5 & 2.7 & 1.2 & 0.6 \\
\hline & & & 1,100 & $\mathrm{Q}, \mathrm{Pl}, \mathrm{Mu}, \mathrm{H}$ & 16.7 & 2.4 & 1.1 & 0.2 \\
\hline & & & 1,200 & $\mathrm{Q}, \mathrm{Pl}, \mathrm{Mu}, \mathrm{H}$ & 70.8 & 2.4 & 1.1 & 0.0 \\
\hline \multirow[t]{7}{*}{ OY } & 6.1 & 0.34 & 600 & $\mathrm{Q}, \mathrm{Pl}, \mathrm{O}, \mathrm{M}$ & 0.5 & 0.6 & 0.3 & 1.2 \\
\hline & & & 700 & $\mathrm{Q}, \mathrm{Pl}, \mathrm{O}, \mathrm{M}$ & 1.54 & 0.45 & 0.20 & 0.29 \\
\hline & & & 800 & $\mathrm{Q}, \mathrm{Pl}, \mathrm{O}, \mathrm{M}$ & 1.18 & 1.20 & 0.54 & 1.02 \\
\hline & & & 900 & $\mathrm{Q}, \mathrm{Pl}, \mathrm{O}, \mathrm{M}$ & 2.75 & 1.61 & 0.72 & 0.59 \\
\hline & & & 1,000 & $\mathrm{Q}, \mathrm{Pl}, \mathrm{O}, \mathrm{H}$ & 4.46 & 1.85 & 0.83 & 0.41 \\
\hline & & & 1,100 & $\mathrm{Q}, \mathrm{Pl}, \mathrm{Mu}, \mathrm{H}$ & 22.20 & 5.43 & 2.43 & 0.24 \\
\hline & & & 1,200 & $\mathrm{Q}, \mathrm{Pl}, \mathrm{Mu}, \mathrm{H}$ & 72.31 & 6.53 & 2.92 & 0.09 \\
\hline
\end{tabular}

\footnotetext{
${ }^{*}$ The vitrification rate has been calculated numerically through the analysis discussed in the present paper using secondary electron images of the surface of the specimens, and the mineral composition information has been obtained through X-ray diffraction (XRD) analysis of powdered specimens.

${ }^{a}$ Chemical compositions (Seger formula) of the three types of clay.

bIdentified minerals by XRD, Q, quartz; Pl, plagioclase; O, orthoclase; M, mica group; K, kaolinite; Mu, mullite; H, hematite; T, talc; E: enstatite.

'SD, standard deviation; SE, standard error; RSD, percentage of relative standard deviation.
}

The profiling function converts the brightness values of each pixel on an image into numerical data of grayscale, and thus specimens having irregular brightness due to a rough surface show a jagged graph. Therefore, by calculating the ratio of the pixel of the plain horizontal line (in contrast to the jagged line) to the total pixel of the observed surface, one can determine the ratio of areas vitrified in the sample.

\section{Preparation of the Specimens}

In this study, we selected three types of clay (OH, OG, OY), which are similar to those used in the pottery excavated from Pung-Nap Mud Castle in their chemical compositions (Moon et al., 2011). The chemical and mineral compositions of the three types of clay samples are presented in Table 1. The samples taken from the three types of clay were pressed with a pressure of $200 \mathrm{kgf} / \mathrm{cm}^{2}$ in identical-sized holders, followed by heat treatment in a Muffle Furnace (APM, Korea) at a temperature of $600-1,200^{\circ} \mathrm{C}$ with a heating rate of $2^{\circ} \mathrm{C} / \mathrm{min}$ to yield a series of samples baked at different temperatures. The specimens were kept at their respective highest temperature for $1 \mathrm{~h}$ and were then cooled down to room temperature at a cooling rate of $2^{\circ} \mathrm{C} / \mathrm{min}$. A total of $21 \mathrm{spec}-$ imens were prepared as stated above and were categorized into three groups: OH $600-1,200$, OG $600-1,200$, and OY $600-1,200$, corresponding to the type of the clay and firing temperature. The specimens were mounted on base plates with epoxy resins and polished until the surfaces became as shiny as a mirror using $1 \mu \mathrm{m}$ of polishing powder. The polished surfaces were then coated with Au to make the surface conductive using a sputtering machine with an operating condition of $10 \mathrm{~mA}$ current for $80 \mathrm{~s}$ at a distance of $5 \mathrm{~cm}$ from the target.

\section{Operating Conditions of SEM}

An SEM (JEOL, JSM-5910LV, Japan) was used to study the microstructure in order to estimate the rate of vitrification. The operating conditions for SEM were same for all specimens: accelerating voltage $20 \mathrm{kV}$, WD $20 \mathrm{~mm}$, and a tilt angle of $0^{\circ}$. The spot size was selected such that the image yields the highest value of the vitrification rate in a specimen. The scan speed and contrast/brightness were also controlled for a maximum resolution and consistent contrast level, respectively. An appropriate magnification rate was carefully chosen by comparing the changes in the ratio of the vitrification rate such that the area under examina- 

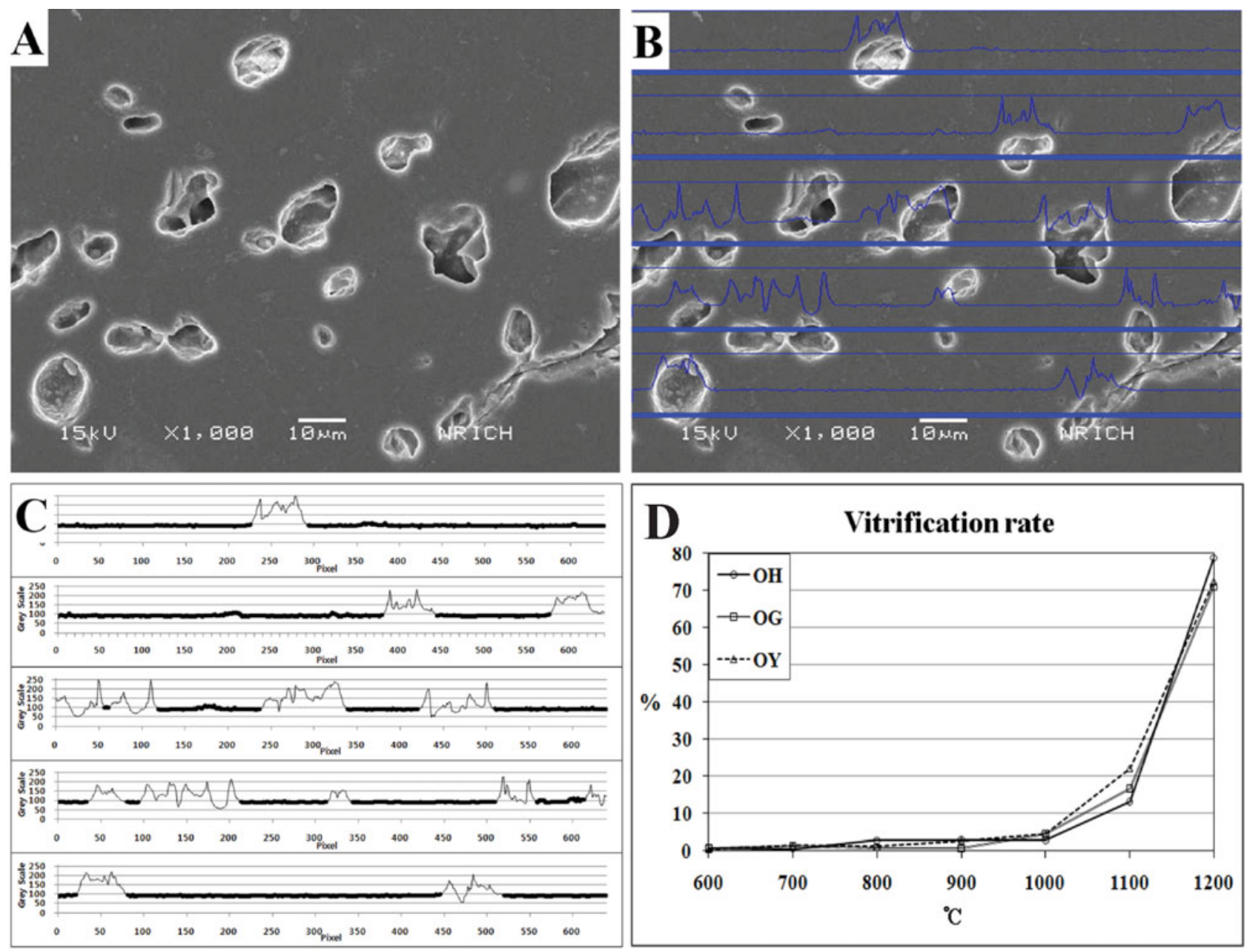

Figure 1. The acquisition process of the vitrification rate (A) an secondary electron images (SEI) image of the vitrified texture of pottery fired at $1,200^{\circ} \mathrm{C},(\mathbf{B})$ transformation of the SEI image to a grayscale value, $(\mathbf{C})$ count of the flat range of the grayscale graph, (D) the vitrification rate calculated from the grayscale graphs of the pottery specimens composed of three types of clay. The vitrification rate increases dramatically for specimens fired at $1,100^{\circ} \mathrm{C}$ and higher, regardless of the clay type.

tion could represent the whole specimen. The experiment was performed on five parts of all specimens.

\section{Measurement Details of the Vitrification Rate and Mineral Composition}

Grayscale values of pixels were determined using the profiling function of an image analysis software (Axio Vision Rel. 4.8, Carl Zeiss, Germany). The number of pixels were counted and converted into a percentage, and the average of the five lines was calculated, as the grayscale values of the vitrified areas had very small variations. This process is shown in Figure 1.

The firing temperature of pottery is typically estimated by assessing the phase transition of the clay material and the presence of high temperature minerals. Mullite is one of the good indicators for estimating the firing temperature. Mullite is formed through decomposition of kaolinite crystals at around $1,100 \mathrm{C}$ upon firing as primary mullite, whereas secondary mullite needle formation occurs around 1,200 C by the reaction between feldspar relict and clay mineral relict (Kingery et al., 1991; Iqbal \& Lee, 1999; Dana \& Das, 2004). XRD analysis (D/MAX-Ultima III, Rigaku, Japan) was also performed for comparison with the SEM experiment. Specimens for the XRD experiment were powdered and dried at $105^{\circ} \mathrm{C}$ for $24 \mathrm{~h}$ and pressed in a glass holder. A $\mathrm{Cu}$ target with $40 \mathrm{kV}$ and $100 \mathrm{~mA}$ was used at a scan condition of $3-7^{\circ}(2 \theta, 1 / \mathrm{min})$ and $17-60^{\circ}(2 \theta, 4 / \mathrm{min})$. The data were analyzed using an ICDS card.

\section{Results}

\section{Measurement Conditions of SEM}

The accelerating voltage, $\mathrm{WD}$, tilt angle, and probe current, which may influence the amount of secondary electrons, were kept constant in order to determine an optimal value for the spot size - a spot size 38 yielded the highest vitrification rate. A spot size $>38$ did not show a stable image because of sample charging, and a size $<38$ showed a low vitrification rate. The measured vitrification rate from the acquired image was compared after application of a quick 
scan (8-10 s) and a fine scan (80 s), which showed only minor differences, although the fine scan image yielded a slightly higher resolution. For comparing RSD (\%) on the basis of the application of different magnification rates $(100 \times, 500 \times, 1,000 \times$, and $1,500 \times)$, it was seen that the result of $1,000 \times$ yields the lowest RSD of the vitrification rate for five different spots of the specimen, suggesting the best condition.

\section{The Vitrification Rate and Mineral Composition}

Specimens fired at $600-1,200^{\circ} \mathrm{C}$ were analyzed with a 38 spot size and 1,000 $\times$ magnification. Many amorphous pores were observed on specimens fired at $600-1,000^{\circ} \mathrm{C}$ as no vitrification process had occurred. Specimens fired at $1,100^{\circ} \mathrm{C}$ showed partial vitrification with partially compact textures and clearer pore edges when compared with lower temperature fired specimens. A compact texture and oval-shaped pores with clear edges were observed on specimens fired at $1,200^{\circ} \mathrm{C}$. The calculated values of the vitrification rate from SEI of the specimens were $<1 \%$ at $600^{\circ} \mathrm{C}$, and $<3 \%$ at $700-900^{\circ} \mathrm{C}, 3-5 \%$ at $1,000^{\circ} \mathrm{C}, 10-25 \%$ at $1,100^{\circ} \mathrm{C}$, and $70 \%$ at $1,200^{\circ} \mathrm{C}$ (Table 1, Fig. 1d). These tendencies were persistent in specimens from all three types of soil. The XRD analysis also agreed with the above-mentioned SEI analysis in that mullite, the high temperature mineral, was detected in the specimens at $1,100^{\circ} \mathrm{C}$ and above, which is consistent with the rapid increase in the vitrification rate calculated above (Table 1). The RSD between the results was very small when the same specimen was analyzed by two different operators under similar operating conditions.

\section{Discussion}

The textural analysis conditions, which influence the number of secondary electrons, and the observation conditions, which have an impact on the last image, need to be established in order to determine the vitrification rate of specimens by SEI of SEM. In this study, we optimized the experimental conditions for quantitative analysis of the vitrification rate values: accelerating voltage, $20 \mathrm{kV}$; working distance, $20 \mathrm{~mm}$; tilt angle, 0 ; spot size, 38; magnification, $1,000 \times$; and scan speed, $8-10 \mathrm{~s}$.

The spot size is proportional to the number of secondary electrons, as a larger spot size allows more emission of incident electrons. However, charge-up on the sample occurs as more incident electrons hit a low conductive specimen, thus damaging it. This charge-up occurred in specimens for the spot size $>38$ may be because of the incident electrons that are not discharged due to the interrupted current paths by improper coating on the rough sample surface. Although this problem can be resolved by making the coating layer thicker, adjustment of the spot size is more effective, as a thick coating layer can distort the morphological information. Measured images with a spot size $<38$ show a lower measurement value of the vitrification rate because of the lack of secondary electrons, taking into consideration the electrical noise, which can contribute to a jagged graph through an amplifying process, thus yielding a poor vitrification rate.

Electron scanning of specimens with a slow speed yields an enhanced resolution of the image because of the increased density, whereas sample charging can occur with an increase in the amount of incident electrons. A contrasting situation occurs when a faster scan speed is used. The vitrification rates obtained by a quick scan $(8-10 \mathrm{~s})$ and a fine scan $(80 \mathrm{~s})$ do not show major differences, suggesting that a quick scan is more appropriate to increase the effectiveness of the analysis and to reduce sample charging.

The magnification of the image can also be an important variable when an uneven specimen such as pottery is analyzed. Classification of vitrification areas with a low magnification rate becomes difficult because of the low resolution, whereas an analysis with a very high magnification can lose the representativeness of the whole specimen as only a specific area is detected. In the present study, we found that the resolution was too rough with a low magnification $(100 \times)$ and only a very limited area was observable at a magnification of $1,500 \times$. Although the measured result of the vitrification rate at both $500 \times$ and $1,000 \times$ seemed adequate, the RSD with $1,000 \times$ was lower than that with $500 \times$, probably because of the uneven distribution of the irregular particles in the specimen. From the observation result of the specimen texture, it has been confirmed that partially vitrified textures appeared over a temperature of $1,100^{\circ} \mathrm{C}$ and a sudden increase in the vitrification rate occurred around the same temperature, demonstrating that the quantified data are coincident with the qualitative analysis of pottery textures by visual observation, which thus proves the validity of present method of quantitative analysis.

Inclusion of mullite, a high temperature mineral, was analyzed by XRD for specimens fired at $1,100^{\circ} \mathrm{C}$ and higher and showed a tendency similar to the result of vitrification rate. The analyses of the identical specimen with two different operators under similar operating conditions show very small deviation, indicating a good reproducibility for the same condition, suggesting that the method presented here can be usefully applied in further research for estimating the firing temperature. The absolute value of the rate of vitrification, however, may not be very meaningful for potteries fired below $1,000^{\circ} \mathrm{C}$ as the value is very small and the noise level is high. Other studies should be considered to analyze these low firing temperatures.

\section{CONCLUSIONS}

In this study, a quantitative method of measuring the vitrification rate of pottery was developed using SEI acquired by SEM on sets of pottery specimens. The acquiring conditions for SEI were established: $20 \mathrm{kV}$ accelerating voltage, $20 \mathrm{~mm}$ $\mathrm{WD}$, and a tilt angle of $0^{\circ}$. In addition, reproducibility was confirmed by comparing two individual results obtained by two operators under similar conditions. A comparison between the vitrification rate and appearance temperature of minerals analyzed by XRD shows that mullite formation 
starts at $1,100^{\circ} \mathrm{C}$, during which the vitrification rate rapidly increases by over $10 \%$, and the result proves that the developed method in this study can be applied to estimate the firing temperature of pottery. However, a further study is necessary to supplement the interruptive factors such as contrast and brightness that cause error of measurement of the vitrification rate during SEM observation. The method using vitrification of pottery texture devised in this study will provide a quantitative basis for evaluation of the firing temperature of pottery hereafter.

\section{ACKNOWLEDGMENT}

This study, which forms a part of the project, was accomplished with support of the Conservation Restoration Technology Research and Development Project, which has been hosted by the National Research Institute of Cultural Heritage of Cultural Heritage Administration.

\section{ReFERENCES}

Andaloro, E., Belfiore, C.M., De Francesco, A.M., Jacobsen, J.K. \& MitтicA, G.P. (2010). A preliminary archaeometric study of pottery remains from the archaeological site of Timpone della Motta, in the Sibaritide area (Calabria-Southern Italy). Appl Clay Sci 53(3), 445-453.

DANA, K. \& DAs, S.K. (2004). Evolution of microstructure in fly ash containing porcelain body on heating at different temperatures. Bull Mater Sci 27, 183-188.

Hein, A., Müller, N.S., Day, P.M. \& Kilikoglou, V. (2008). Thermal conductivity of archaeological ceramics: The effect of inclusions, porosity and firing temperature. Thermochim Acta $480,35-42$.

IQbAL, Y. \& LeE, W.E. (1999). Fired porcelain microstructures revisited. J Am Ceram Soc 82, 3584-3590.

Kilikoglou, V. (1994). Scanning electron microscopy. In Ceramic Regionalism in Prepalatial Central Crete: The Mesara Imports at
EMI to EMIIA, Knossos, D.E. \& Day, P.M. (Eds.), Annual of the British School at Athens, 89, 1-87.

Kingery, W.D., Bowen, H.K. \& Uhlman, D.R. (1991). Introduction to Ceramics, 2nd ed. Singapore: John Wiley \& Sons.

Maniatis, Y., Simopoulos, A., Kostikas, A. \& Perdikatsis, V. (1983). Effect of a reducing atmosphere on minerals and iron oxides developed in fired clays: The role of Ca. J Am Ceram Soc 66, 773-781.

Maniatis, Y. \& Tite, M.S. (1975). Scanning electron microscope examination of the bloating of fired clays. Trans $\mathrm{J} \mathrm{Br}$ Ceram Soc 74, 229-232.

Maniatis, Y. \& Tite, M.S. (1978). Ceramic technology in the Aegean world during the Bronze Age. In Thera and the Aegean World, vol. 1, Doumas, C. (Ed.), pp. 483-492. London: The Thera Foundation.

Maniatis, Y. \& Tite, M.S. (1981). Technological examination of Neolithic-Bronze Age pottery from central and southeast Europe and from the Near East. J Archaeol Sci 8, 59-76.

Moon, E.J., Kang, H.J., Han, M.S. \& LeE, H.H. (2011). A study on the categorization method of earthenware from Pung-Nap Mud Castle based on scientific data. The Baekje Hakbo 5, 57-90.

Moropoulou, A., Bakolas, A. \& Bisbikou, K. (1995). Thermal analysis as a method of characterizing ancient ceramic technologies. Thermochim Acta 269-270, 743-753.

Noll, W., Holm, R. \& Born, L. (1975). Painting of ancient ceramics. Angew Chem Int Ed Engl 14, 602-619.

Sandrolini, F., Moriconi, G., Veniali, F. \& Zappia, C. (1993). Principles and applications of pore structure characterization. International Symposium RILEM/CNR, Haynes, J.M. \& Doria, P.R. (Eds.), Milan, Italy, pp. 291-297.

Van Olphen, H. \& Fripat, J.J. (1979). Data Handbook for Clay Materials and Other Non-Metallic Minerals, 1st ed. London: Pergamon Press.

Velraj, G., Janaki, K., Musthafa, A.M. \& Palanivel, R. (2009). Estimation of firing temperature of some archaeological pottery shreds excavated recently in Tamil Nadu, India. Spectrochim Acta A Mol Biomol Spectrosc 72, 730-733. 